\title{
Níveis de Controle de Diloboderus abderus (Sturm) em Trigo no Plantio Direto
}

\author{
Mauro T.B. Silva ${ }^{1}$ \\ ${ }^{1}$ Fundacão Centro de Experimentacão e Pesquisa Fecotrigo, FUNDACEP, \\ Caixa postal 10, 98100-970, Cruz Alta, RS.
}

\author{
An. Soc. Entomol. Brasil 26(3): 435-440 (1997) \\ Control Levels of Diloboderus abderus (Sturm) in Wheat \\ Crop under No-Tillage
}

\begin{abstract}
This work was carried out in the 1991, 1992 and 1994 growing seasons, in Cruz Alta, Rio Grande do Sul State. The objective was to evaluate the infestation levels and damage of Diloboderus abderus (Sturm) in wheat under no-tillage. Infestations above 5.0 larvae $/ \mathrm{m}^{2}$ caused significant reductions on yield when compared to uninfested plants. Increasing number of larvae $/ \mathrm{m}^{2}$ increased damaged plants with decreased plant population, number of ears, plant biomass and yield. Control levels were of 5.4 in 1991, 3.0 in 1992 and 6.1 larvae $/ \mathrm{m}^{2}$ in 1994. Significant negative correlations were observed between number of larvae and plant population, number of ears, plant biomass and yield. Significant positive correlations were obtained between yield and plant population, number of ears and plant biomass. Results of the insect damage suggested the control level of 5.0 larvae $/ \mathrm{m}^{2}$ as indicator for wheat seed treatment with insecticides.
\end{abstract}

KEY WORDS: Insecta, larvae, damaged plants, Triticum aestivum.

RESUMO - Este trabalho foi conduzido nas safras agrícolas de 1991, 1992 e 1994, em Cruz Alta, no Rio Grande do Sul. O objetivo foi avaliar níveis de infestação e danos de Diloboderus abderus (Sturm) em trigo no plantio direto. Infestações a partir de 5,0 larvas $/ \mathrm{m}^{2}$ causaram reduções significativas na produtividade das plantas de trigo em relação a testemunha não infestada. Aumentando o número de larvas $/ \mathrm{m}^{2}$ ocorre danos nas plantas e, conseqüentemente, decresce a população de plantas, o número de espigas, a massa seca da parte aérea e a produtividade. Os níveis de controle obtidos foram de 5,4 larvas $/ \mathrm{m}^{2}$ (1991), 3,0 larvas $/ \mathrm{m}^{2}$ (1992) e 6,1 larvas $/ \mathrm{m}^{2}$ (1994). Foram observadas correlações negativas significativas do número de larvas com a população de plantas, o número de espigas, a massa seca da parte aérea e a produtividade, e correlações positivas significativas da produtividade com a população de plantas, o número de espigas e a massa seca da parte aérea. Baseado nos danos produzidos pelo inseto, sugere-se o nível de controle de 5,0 larvas $/ \mathrm{m}^{2}$ como indicador para tratamento de sementes de trigo com inseticidas.

PALAVRAS-CHAVE: Insecta, larvas, plantas danificadas, Triticum aestivum. 
Diloboderus abderus (Sturm) é um coleóptero, da família Melolonthidae, conhecido pelos agricultores como "coró-daspastagens". O inseto é polífago, atacando pastagens naturais ou artificiais, gramados e cultivos de lavouras como aveia, batatinha, cana-de-açucar, centeio, cevada, colza, girassol, linho, milho, soja, sorgo e trigo, cultivos de hortaliças como alface, beterraba, couve e repolho e cultivos de forrageiras como alfafa, azevém, festuca e trevo branco (Silva et al. 1968, Morey \& Alzugaray 1982, Alvarado 1983).

$\mathrm{O}$ inseto tem grande potencial de dano, pois as larvas reduzem o número de plantas por unidade de área pela ação direta sobre sementes, raízes ou plântulas. Baucke (1965) encontrou infestações da ordem de 33 e 49 larvas $/ \mathrm{m}^{2}$, em campos de pecuária, com pastagem natural, observando raízes de plantas destruídas e deposição de terra das escavações na superficie do solo. O volume depositado foi mais acentuado após chuvas, quando as larvas procuram desobstruir as galerias, cobrindo as pastagens e, consequentemente, diminuindo a capacidade de lotação dos campos. Galarza (1972) constatou perdas de até $1.200 \mathrm{~kg} / \mathrm{ha} \mathrm{de}$ milho, quando a espécie $D$. abderus estava presente em maioria dentro da população de insetos de solo ocorrentes na área. Morey \& Alzugaray (1982) observaram manchas em "reboleiras", nas quais as populações variaram entre 25 e 250 larvas $/ \mathrm{m}^{2}$ e estimaram a invasão do inseto em mais de 500.000 hectares.

Alvarado (1980, 1989), relata que o efeito prejudicial de larvas é evidente na fase inicial de desenvolvimento das plantas de milho, quando as densidades são superiores a 4 exemplares $/ \mathrm{m}^{2}$. Gassen (1993) sugeriu esse mesmo nível, pois causaria uma redução de $10 \%$ na população de plantas de aveia e trigo.

O objetivo desse trabalho foi obter informacões dos efeitos do ataque das larvas de D.abderus e do seu nível de controle à cultura do trigo em áreas de plantio direto.

\section{Material e Métodos}

Os experimentos foram conduzidos na Fundacep Fecotrigo, em Cruz Alta - RS, num Latossolo Vermelho Escuro distrófico, textura argilosa, com 55 a $60 \%$ de argila e 3,0 a 3,2\% de matéria orgânica, durante as safras 1991, 1992 e 1994, em áreas experimentais com 2 e 4 anos de plantio direto.

O trigo, cultivares CEP 21 - Campos (1991 e 1992) e CEP 24 - Industrial (1994), foi semeado com 330 sementes aptas $/ \mathrm{m}^{2}$ e espaçamento de $0,20 \mathrm{~m}$. O delineamento experimental usado foi de blocos ao acaso com cinco repetições (1991 e 1992) e quatro repetições (1994) e cinco tratamentos, representados por níveis de infestação de larvas de $D$. abderus em parcelas de cinco fileiras de 1,0 $\mathrm{m}$ de comprimento, perfazendo uma área de $1,0 \mathrm{~m}^{2}$. As semeaduras ocorreram em 15/06 (1991 e 1992) e 08/06 (1994). Antes da semeadura do trigo larvas de $2^{\circ}$ e $3^{\circ}$ ínstares foram colocadas nas parcelas, numa profundidade de 10 a $15 \mathrm{~cm}$, nos seguintes níveis populacionais: $0,5,10,20$ e 40/ $\mathrm{m}^{2}$. O tempo de infestação foi durante todo o ciclo das plantas de trigo. Para evitar a disseminação das larvas entre as parcelas experimentais, placas galvanizadas quadradas (1,5 $\mathrm{m}$ de lado e $0,20 \mathrm{~m}$ de altura), enterradas $0,05 \mathrm{~m}$ no solo, individualizando cada parcela, foram mantidas até a emergência dos adultos, nas safras 1992 e 1994.

A adubação de base foi de 15, 60 e $60 \mathrm{~kg} /$ ha, respectivamente, de N, P e K. Em cobertura, usou-se $20 \mathrm{~kg} / \mathrm{ha}$ de $\mathrm{N}$ em duas épocas de aplicação. O controle de plantas daninhas e de tratamentos fitossanitários foram realizados de acordo com as recomendações para a cultura. Foram avaliados: população inicial de plantas, número de espigas, quantidade de massa seca da parte aérea e produtividade de grãos por parcela. Para a avaliação da massa seca, plantas de trigo foram cortadas rente ao solo logo após a colheita das espigas e colocadas em estufa a $70^{\circ} \mathrm{C}$, durante 48 horas. Para produtividade, as espigas foram trilhadas e 
corrigida a umidade de grãos para $13 \%$ após a pesagem.

As análises de variância dos dados de produtividade foram realizadas, para cada safra agrícola, considerando critérios básicos de estatística, como normalidade de resíduos e homogeneidade de variância. A relação entre a produtividade obtida e o nível de infestação de larvas foi expressa pelas análises de regressão e pelos pontos de nível de controle (NC). Esses pontos foram calculados a partir de: $\mathrm{Z}=$ custo em reais da aplicação (gramas $\left./ \mathrm{m}^{2}\right) ; \mathrm{Cs}=$ valor em reais da semente de trigo (0,00013/grama); $\mathrm{Ci}=$ custo em reais do inseticida via tratamento de sementes $\left(0,003 / \mathrm{m}^{2}\right) ; \mathrm{b}=$ coeficiente " $\mathrm{b}$ " da equação; $\mathrm{X}(\mathrm{NC})=$ número de larvas $/ \mathrm{m}^{2} ; \mathrm{Y}(\mathrm{X}=0)=$ coeficiente " a" da equação ou produtividade sem o custo da aplicação e $\mathrm{Y}[\mathrm{X}(\mathrm{NC})]=$ produtividade com o custo da aplicação. Assim, o custo da aplicacão foi obtido pela fórmula $\mathrm{Z}=1$. Ci / Cs ; o número de larvas/ $\mathrm{m}^{2}$ foi calculado pela fórmula $\mathrm{X}(\mathrm{NC})=\mathrm{Z} / \mathrm{b}$ e a produtividade com o custo da aplicação foi determinado pela fórmula $\mathrm{Y}[\mathrm{X}(\mathrm{NC})]=$ $\mathrm{Y}(\mathrm{X}=0)-\mathrm{Z}$. Determinou-se também as correlações simples entre as variáveis larvas de $D$. abderus, população inicial de plantas, número de espigas, massa seca da parte aérea e produtividade e entre produtividade, população inicial de plantas, número de espigas e massa seca da parte aérea.

\section{Resultados e Discussão}

A partir de 5,0 larvas $/ \mathrm{m}^{2}$ foram observadas diferenças nas produtividades das plantas de trigo em comparação à testemunha com ausência do inseto, nas três safras agrícolas e, principalmente, na safra 1994. (Fig. 1).

As análises de regressão entre produtividade média de trigo por parcela e número de larvas de D. abderus $/ \mathrm{m}^{2}$ mostraram que o melhor ajuste ocorreu com a regressão quadrática, mas optou-se pelo ajuste linear devido à pequena contribuição do efeito quadrático e dificuldade no cálculo dos níveis de controle. Os valores dos coeficientes de determinação obtidos para regressão linear foram de 0,98 (1991), 0,93 (1992) e 0,97 (1994) e significativos (Fig. 1). Não foi realizada análise de regressão conjunta dos três anos, devido a interação anos $\mathrm{x}$ tratamentos ter sido significativa. Isto ocorreu, provavelmente, devido a longa estiagem verificada no mês de agosto, que afetou a produtividade em 1991. Inclusive, percebe-se que em todos os níveis testados e, principalmente, nos mais elevados de infestação, aumentaram o estresse das plantas, que não conseguiram recuperação, como ocorreu nas safras 1992 e 1994.

As correlações entre as variáveis larvas de $D$. abderus com a população inicial de plantas, o número de espigas, a quantidade de massa seca da parte aérea e a produtividade foram negativas e significativas (Tabela 1). As correlações entre a produtividade com a população inicial, o número de espigas e a massa seca da parte aérea foram positivas e significativas. Esses resultados significam que com o aumento do nível de infestação de larvas $/ \mathrm{m}^{2}$, a população inicial, o número de espigas, a quantidade de massa seca da parte aérea e a produtividade de plantas de trigo são afetadas. Esses dados indicam também que a contagem de larvas pode ser utilizada para amostragem do nível populacional do inseto, porque esta correlacionada com produtividade de plantas de trigo.

Os valores dos coeficientes de determinação e os coeficientes b negativos das equações (Fig. 1), além dos coeficientes de correlação negativos (Tabela 1) demosntraram alta relação entre produtividade de trigo com o nível de infestação de D. abderus, indicando que decresce a produtividade com o aumento do número de larvas $/ \mathrm{m}^{2}$. Os coeficientes de correlação positivos (Tabela 1) evidenciaram alta relação entre a população inicial, o número de espigas e a massa seca da parte aérea com a produtividade das plantas de trigo, indicando que com a redução do número de plantas e de espigas e da quantidade de massa seca das plantas ocorre perdas na produtividade.

Considerando o custo dos insumos (semente de trigo indústria e inseticida para 

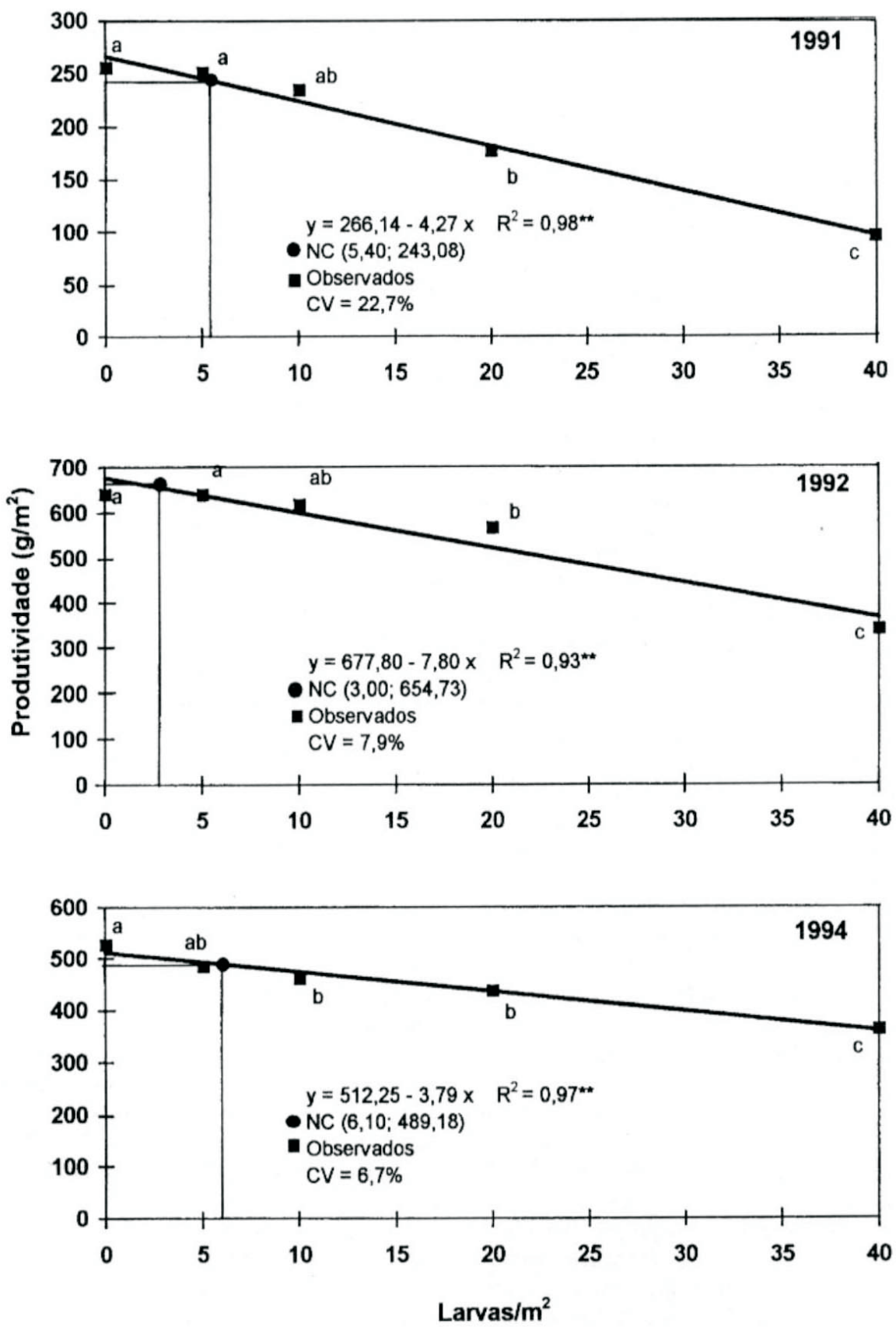

Figura 1. Regressão linear entre produtividade de plantas de trigo e níveis de infestação de Diloboderus abderus e nível de controle (NC), durante três safras agrícolas. Valores observados de mesma letra não são significativamente diferentes pelo teste de Duncan $(\mathrm{P} \leq$ $0,05)$. 
tratamento de sementes) e os cálculos feitos para o tamanho de parcelas usadas nesta pesquisa, encontrou-se o custo da aplicação (Z) no eixo Y de 23,07 gramas de trigo, que é danos produzidos pelas larvas de $D$. Abderus às plantas de trigo, sugere-se o nível de controle de 5,0 larvas $/ \mathrm{m}^{2}$ como indicador para uso de inseticidas via tratamento de sementes.

Tabela 1. Coeficientes de correlação (r) simples obtidos entre larvas de Diloboderus abderus com a população inicial, o número de espigas, a massa seca da parte aérea e a produtividade de trigo, e entre a produtividade com a população inicial, o número de espigas e a massa seca da parte aérea de trigo.

\begin{tabular}{|c|c|c|c|}
\hline \multirow{3}{*}{ Variáveis } & \multicolumn{3}{|c|}{ Coeficientes e probabilidades de correlações ${ }^{1}$} \\
\hline & \multicolumn{3}{|c|}{ Safras agrícolas de trigo } \\
\hline & 1991 & 1992 & 1994 \\
\hline Larva $x$ população inicial & $r=-0,47(0,0162 *)$ & $\mathrm{r}=-0,81(0,0001 *)$ & $\mathrm{r}=-0,80(0,0001 *)$ \\
\hline Larva x número de espiga & $r=-0,79(0,0001 *)$ & $r=-0,83(0,0001 *)$ & $r=-0,83\left(0,0001^{*}\right)$ \\
\hline Larva $\mathrm{x}$ massa seca & $r=-0,76\left(0,0001^{*}\right)$ & $r=-0,68(0,0002 *)$ & $r=-0,92(0,0001 *)$ \\
\hline Larva $\mathrm{x}$ produtividade & $r=-0,71(0,0001 *)$ & $\mathrm{r}=-0,78\left(0,0001^{*}\right)$ & $r=-0,87(0,0001 *)$ \\
\hline Produtividade x população inicial & $r=0,58(0,0021 *)$ & $\mathrm{r}=0,82(0,0001 *)$ & $r=0,86(0,0001 *)$ \\
\hline Produtividade $\mathrm{x}$ número de espigas & $r=0,95(0,0001 *)$ & $r=0,90(0,0001 *)$ & $r=0,88\left(0,0001^{*}\right)$ \\
\hline Produtividade $\mathrm{x}$ massa seca & $r=0,80(0,0001 *)$ & $\mathrm{r}=0,81\left(0,0001^{*}\right)$ & $r=0,86(0,0001 *)$ \\
\hline
\end{tabular}

${ }^{1}$ Entre parênteses, as probabilidades das correlações (* significativo a $5 \%$ de probabilidade) estimadas pelo teste $t$.

igual ao dano causado pelo inseto. Esse valor dividido pelo coeficiente " $\mathrm{b}$ " das equações determinou em 5,4 larvas $/ \mathrm{m}^{2}$ (1991), 3,0 larvas $/ \mathrm{m}^{2}$ (1992) e 6,1 larvas $/ \mathrm{m}^{2}$ (1994) (Fig. 1) o nível de controle $\mathrm{X}(\mathrm{NC})$ do inseto. Essas densidades $/ \mathrm{m}^{2}$, são os números de larvas ajustados para os mesmos níveis equivalentes ao custo da aplicação $\mathrm{Y}[\mathrm{X}(\mathrm{NC})]$, que foram de 243,08; 654,73 e 489,18 gramas de trigo às safras agrícolas de 1991, 1992 e 1994, respectivamente (Fig. 1).

Os resultados obtidos concordam com Gassen (1993), que encontrou um consumo de 10 plantas por larva em dois meses e inferiu que uma população de 4 larvas $/ \mathrm{m}^{2}$ reduz em $10 \%$ a população de plantas de trigo. Alvarado (1980) relata apenas que os danos das larvas deste inseto são mais evidentes quando a população atinge 4 larvas $/ \mathrm{m}^{2}$, em áreas semeadas com milho. Entretanto, este nível de controle para esta cultura não foi encontrado na literatura.

Em conclusão, baseado nos resultados dos
Este valor foi o número de larvas aproximado da média das três safras $\left(4,8\right.$ larvas $\left./ \mathrm{m}^{2}\right)$, ajustado para o nível equivalente ao custo da aplicação. No entanto, o nível de controle pode variar de uma área para outra dentro duma mesma região devido a clima, solo, fertilidade, época de semeadura, variedade, inimigos naturais e custos de sementes e inseticidas, além de sucessão ou rotação de culturas. Assim, tais fatores, que não foram uniformizados neste estudo, podem influenciar o ajustamento do nível de controle ideal, devendo o nível de controle sugerido ser enquadrado apenas como um parâmetro relativo na tomada de decisão de estratégias de controle desse inseto.

\section{Agradecimentos}

Ao Professor Lindolfo Storck, do Departamento de Fitotecnia do CCR/UFSM, pela colaboração e sugestões com as análises estatísticas. 


\section{Literatura Citada}

Alvarado, L. 1980. Plagas: insectos del suelo. In A.L. Damilano \& L.F. Brugnoni, coord. Coleccion Principales Cultivos de la Argentina; El cultivo del maíz. Buenos Aires, INTA, p. 88-94.

Alvarado, L. 1983. Dãnos de insectos de suelo en semillas de plantas cultivadas. Pergamino, INTA/EERA, Inf. Tec. 180. $7 \mathrm{p}$.

Alvarado, L. 1989. Amostragem de insetos de solo. In Ata Reunião Sul-Brasileira de Insetos de Solo, 2, Londrina, p. 34-37.

Baucke, O. 1965. Notas taxonômicas e biológicas sobre Diloboderus abderus (Sturm, 1826) Coleoptera-ScarabaeidaeDynastinae. Rev. Fac. Agron. Veter. 7:113-135.

Galarza, J. 1972. Control de insectos de suelo que prejudican al maíz. INTA/EERA, Inf. Tec. $115.11 \mathrm{p}$.
Gassen, D.N. 1993. Corós associados ao sistema plantio direto. In Plantio direto no Brasil, Aldeia Norte, ed. Passo Fundo, p. 141-149.

Morey, C.S. \& R. Alzugaray. 1982. Biologia y comportamiento de Diloboderus abderus (Sturm) (Coleoptera: Scarabaeidae). Dir. San. Veg. Bol. Téc. 5, 44 p.

Silva, A.G.d'A., C.R. Gonçalves, O.M. Galvão, A.G.L. Gonçalves, J. Gomes, M.N. Silva \& L. de Simoni. 1968. Quarto catálago dos insetos que vivem nas plantas cultivadas do Brasil; seus parasitos e predadores. Rio de Janeiro, Min. Agric., tomo 1, pt. 2, 622p.

Recebido em 29/04/97. Aceito em 08/09/97. 